\title{
Radioactive Dust in the Air
}

\author{
by \\ N. Yano and H. Naruse \\ Meteorological Research Institute
}

(Received March 30, 1956)

\begin{abstract}
After various kinds of the dust collector were inspected and compared in order to observe radioactivity in the air, the electric dust collector was proved effective for the purpose.

Natural radioactivity in the air averages some $10^{-16} \mathrm{C} \mathrm{cm}^{-3}$, which is mostly due to Radon daughter and Thoron daughter. The relation between suction time and saturated time of natural radioactivity was studied.

Also is reported the diurnal variation of artificial radioactivity in the air from November 1954 to March 1956. Its activity reached some $10^{-7} \mu \mathrm{c} / \mathrm{l}$ at maximum.
\end{abstract}

\section{Introduction}

Since the H-bomb test at the Bikini Atoll in the spring of 1954, to investigate the atmospheric contamination has become necessary not only from the viewpoint of meteorology but also from environmental sanitation.

In this paper the authors report on the result of the observation from November 1954 to March 1956 and its method of measurement.

\section{Method of measurement}

There are two methods of investigating the atmospheric contamination; 1) to measure the radioactivity of rain water, which has been generally used, 2) to measure the radioactivity of the dust in the air [1], [2].

In the first method rain drops capture radioactive dust efficiently, but meteorological conditions are influential, and, above all, no samples can be obtained without rain. In the second, samples are obtained constantly under the same condition, while collection efficiency is not so good.

In the last method of collecting atmospheric dust, various dust collectors are available: Impinger, Cascade impactor, Thermal precipitator, Filter paper dust sampler, Electric precipitator, etc. The Electric precipitator was employed in our observation for such reasons as will be presented in the following section.

There are two types of Electric precipitator: A-C precipitator and Electrostatic precipitator. The collection rate of those precipitators are almost the same [2]. 


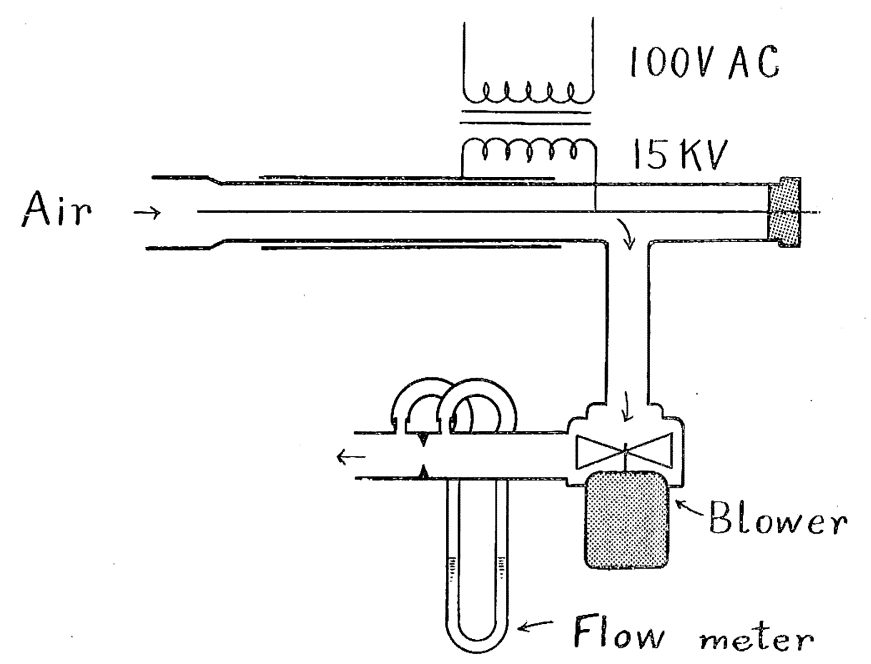

Fig. 1. The electric precipitator.

In the observation the A-C type was mostly employed. As shown in Fig. 1, it is the same type as designed by P. Drinker [1], composed of three parts; power supply, precipitation tube, and suction equipment.

The power supply is served with 15,000 volts through the lumionous tube transformer from AC lighting current. The precipitation tube is the T-type one made of pyrex glass $3 \mathrm{~cm}$ in diameter and $0.1 \mathrm{~cm}$ thick. An

inner electrode is a platinum wire of $0.03 \mathrm{~cm}$ in diameter stretching through the center of glass, and the other electrode is covered with 12 mesh copper screen wrapped tightly around the glass tube.

The blower of 40 litres per minute is used to suck the air in. The flux of air can be read at the water level in a U-tube flow-meter.

The Electrostatic precipitator is supplied with 10,000 to 15,000 volts through the radioamplifier $(140 \mathrm{KC})$ from 100 volts A-C line [2].

The inlet is installed 2 meters above the ground and the air is sucked in 5 hours or so per day, some 10 cubic meters in suction volume. The dust which has attached to the inner wall of the precipitation tube is washed in water and further washed off in a beaker with a rubber-tipped glass bar. The following procedures are the same as in the case of rain water.

The samples are measured more than 24 hours after collection to avoid the influences of the natural radioactive substances.

Each sample is measured by Kaken Model-32 or Decatron beta counter. $1 \mathrm{~cm}$ is the distance between mica window and the sample.

\section{Collection efficiency of the radioactive dust}

Before discussing about the dust collector, the relation between radioactivity in rain drops and the atmospheric dust shall be taken up for consideration. It has been already known that rain drops capture radioactive dust in the air. The decrease of the dust particles in the air caused by rain water will be expressed in the following formula [3]:

$$
N=N_{0} e^{-\frac{3 E R}{4 r}} .
$$

Here, $N_{0}$ indicates the number of the dust particles which are initially contained in the air, $E$ collection rate, $r$ radius of a rain drop and $R$ precipitation amount. 
Indicating the average radioactivity of the dust particle as $\vec{A}$, the radioactivity of the dust in the air $A_{a}$ is written as follows:

$$
A_{a}=\bar{A} N_{0} e^{-\frac{3 E R}{4 r}} \text {. }
$$

On the contrary, radioacivity of rain water will increase the amount of precipitation. This relation is expressed in the following.

$$
A_{R}=H \cdot \vec{A}\left(N_{0}-N\right)=H \cdot \bar{A} \cdot N_{0}\left(1-e^{-\frac{3 E R}{4 r}}\right) .
$$

In this formula $A_{R}$ indicates total radioactivity in case of rain-fall $R$, and $H$ the generating level of rain. The formula (3) shows with good satisfaction the radioactivity of rain water [4], [5]. It means that the number of Aerosol particles reduces by half with $0.46 \mathrm{~mm}$ rain fall in case an Aerosol particle is $8 \mu$ in radius, a rain drop is $0.4 \mathrm{~mm}$ in radius, and collection efficiency is 0.8 [3]. From the above-mentioned, it is known that rain will capture radioactive dust with high efficiency.

In case of collecting dust in the air with the dust collector, the flux of the air and collection efficiency for Aerosol particles are the first consideration. The collection efficiency of the Thermal precipitator is nearly $100 \%$ for particles smaller than $10^{-4} \mathrm{~cm}$ in radius, but the flux is very small. And the Impinger, the Impacter and the Filter paper dust collector would increase the flux of air, but their collection efficiency for particles smaller than $10^{-4} \mathrm{~cm}$ decreases. On the contrary, the Electric precipitator is favoured with the advantages as regards these conditions and so it was employed finally.

\begin{tabular}{|c|c|c|c|c|c|c|c|c|}
\hline Date & Instrument & & Suction $h$ & urs & $\begin{array}{l}\text { Suction } \\
\text { volume }\end{array}$ & $\begin{array}{l}\text { Back- } \\
\text { ground }\end{array}$ & $\begin{array}{l}\text { Net count- } \\
\text { ing rate }\end{array}$ & $\begin{array}{l}\text { Count per } \\
10 \mathrm{~m}^{3}\end{array}$ \\
\hline \multirow[t]{2}{*}{12.10} & Electric precipitator & $(\mathrm{E})$ & $\begin{array}{c}\text { Time } \\
0700-1200\end{array}$ & $\begin{array}{c}\text { Hour } \\
5.0\end{array}$ & $\begin{array}{r}\mathrm{m}^{3} \\
12.0\end{array}$ & $\begin{array}{c}\text { c.p.m. } \\
21.2\end{array}$ & $\begin{array}{l}\text { c.p.m. } \\
21.3\end{array}$ & $\begin{array}{l}\text { c.p.m. } \\
17.5\end{array}$ \\
\hline & Impinger & ( I ) & $0700-1200$ & 5.0 & 12.3 & 22.7 & 1.9 & 1.5 \\
\hline \multirow[t]{2}{*}{12.11} & & (E) & $0700-1140$ & 4.7 & 9.7 & 20.8 & 12.3 & 12.7 \\
\hline & & ( I ) & $0700-1200$ & 5.0 & 12.3 & 20.8 & 0.3 & 0.2 \\
\hline \multirow[t]{2}{*}{12.13} & & $(\mathrm{E})$ & $0750-1200$ & 4.2 & 10.1 & 19.8 & 30.9 & 306 \\
\hline & & (I) & $0750-1200$ & 4.2 & 10.3 & 19.8 & 1.3 & 1.3 \\
\hline
\end{tabular}

Table 1. The comparison of Electric precipitator with Impinger at CMO, 1954.

Concerning the size of radioactive dust particles and the distribution of radioactivity, there are some data on natural radioactivity obtained by WILKENING [6]. Separating the particles by their mobility and measuring their individual activity, he reports that the greater parts are distributed into the particles of 0.001 to $0.04 \mu$ in radius.

Considering that the collection efficiency of radioactive substance by the Electric precipitator is as much as ten times that of the Impactor or the Filter paper, it is understood that the greater parts of radioactive substance attach to such minute particles. 


\section{Natural radioactivity of the sample}

In radioactivity immediately after the collection of the samples, the decay of natural radioactivity is recognized. An given in Fig. 2 and Fig. 3, it is due to Radon and Thoron daughters contained in the air. Half-life is some 30 minutes and 11 hours respectively. The average of this radioactivity is nearly $10^{-16} \mathrm{C} \mathrm{cm}^{-3}$.

The decay 4 to 5 hours after the collection is given in Fig. 2. Apparent half-life is 39.6 minutes on an average of 19 observations. The defection of the decay curve is seen always 2 to 3 hours after the collection of the sample.

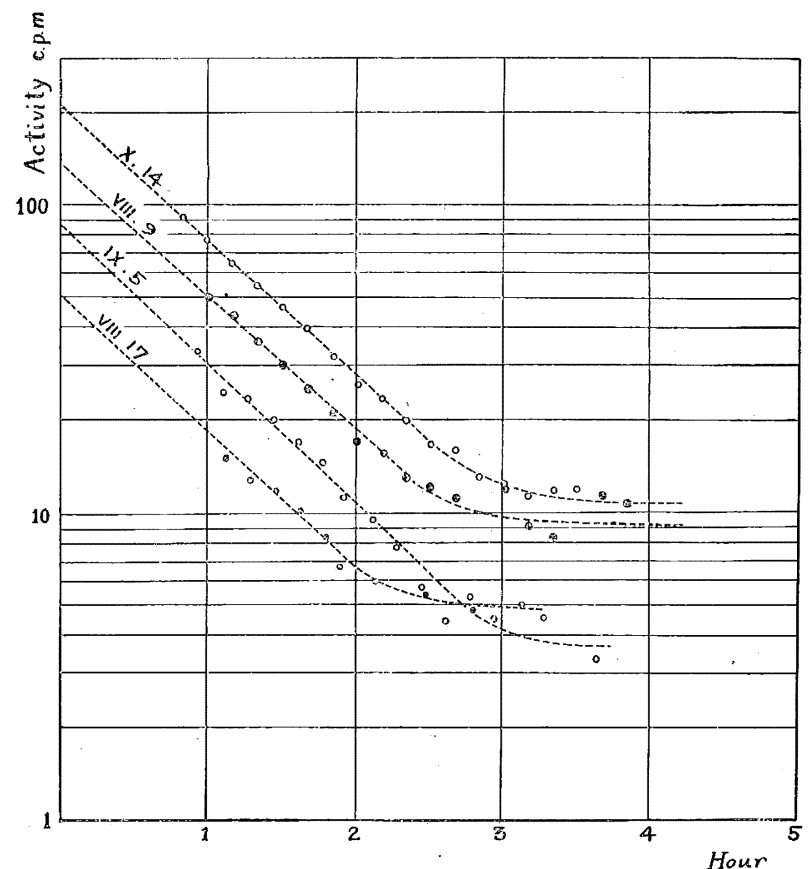

Fig. 2. The decay curve 3 or 4 hours after the collection.

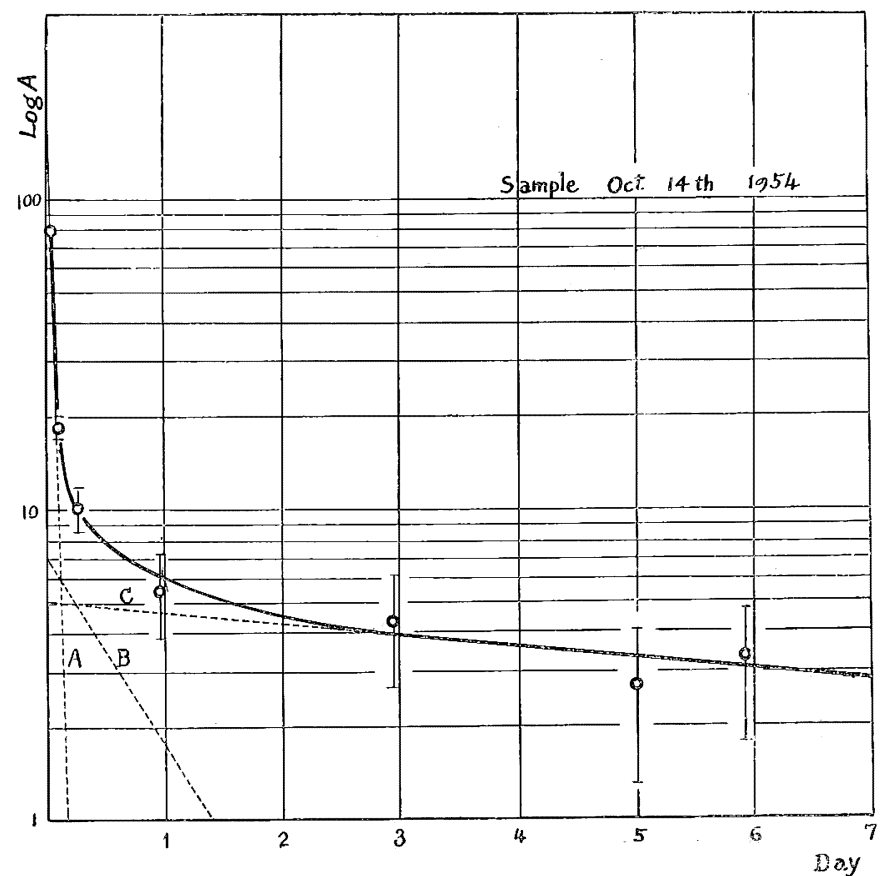

Fig. 3. The decay curve during a week after the coliection. A : the decay of $r_{a}(B+C)$; B: the decay of $T h B ; \mathrm{C}$ : the decay of fission product. 
The appearance of the decay is mostly due to the influences by Radium $B$ and Radium C.

Fig. 3 shows the decay curve during the week after collection and that is an example in which Thorium B is recognized [7]. After the disapperance of Thorium $B$ radioactivity, that of the fission product only remained. The decay of fission product indicates the function of time after the detonation.

In collecting the radioactive dust it must be paid consideration that radioactivity reaches the saturated state with the prolongation of suction time on account of short half-life. This relation is expressed:

$$
\frac{d N}{d t}=V C-N \lambda \rightarrow 0
$$

where, $N$ the number of atom on the colecting tube $\lambda$ disintegration contstant, $V$ suction velocity, $C$ Atomic concentration of the air.

\section{Diurnal variation of the artificial radioactivity}

Fig. 4 shows the measured value of artificial radioactivity of the dust in the air from November 1954 to March 1956.

During the period the peaks were seen four times; November $4 \sim 10,1954$,

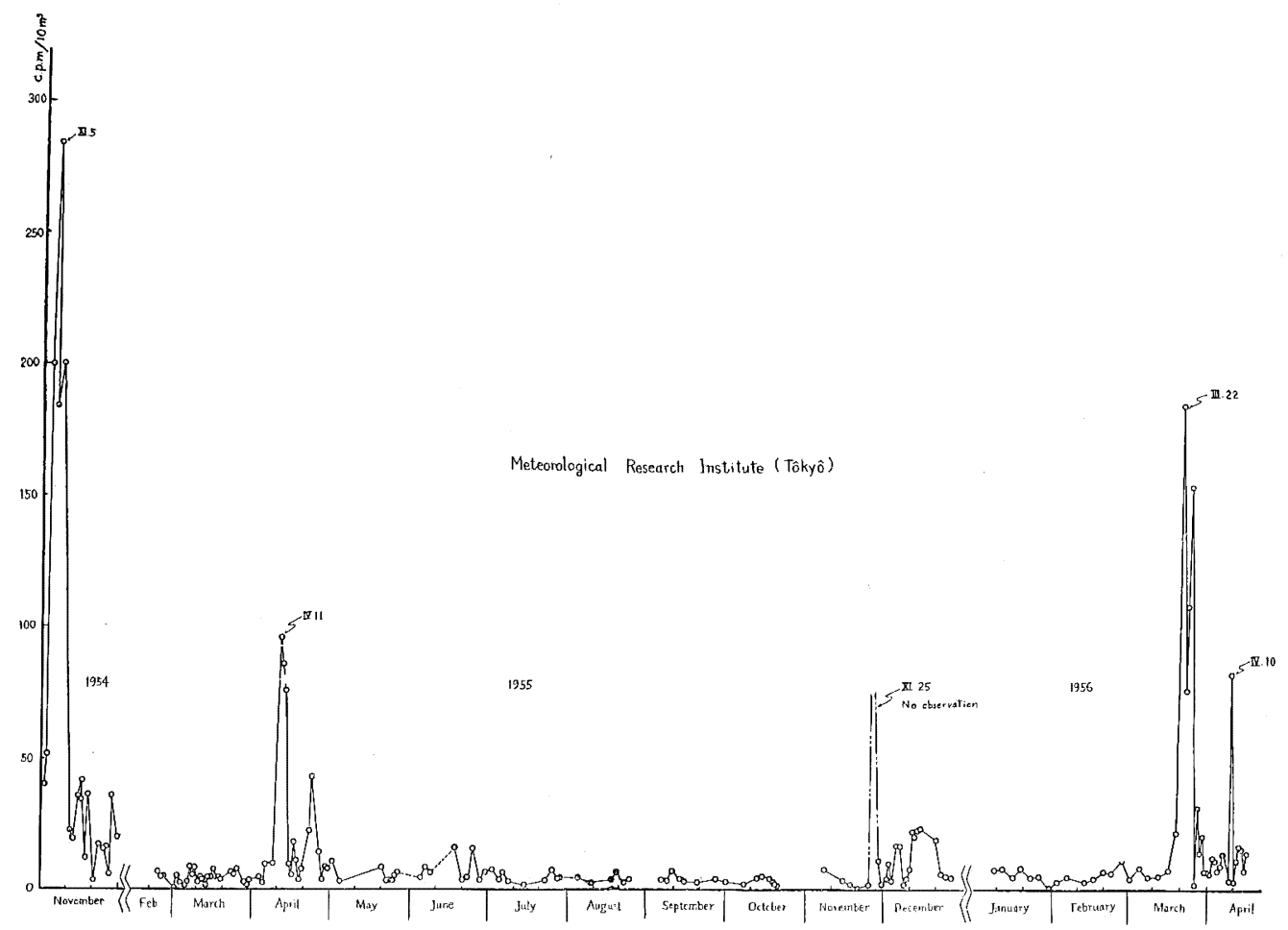

Fig. 4. The measured value of artificial radioactivity of the dust in the air November 1954 to March 1956. 
April 11, 1955, November 25, 1955 and March 22, 1956.

Presumptions on these detonations are shown in Table 2.

Table 2. The presumption on the detonation from November 1954 to March 1956.

\begin{tabular}{|c|c|c|c|}
\hline Observation date & $\begin{array}{l}\text { Presumption of } \\
\text { detonation date }\end{array}$ & Detonation spot & Maximum activity \\
\hline $\begin{array}{l}\text { Nov. } 4 \sim 10,1954 \\
\text { Apr. } 11 \sim 13,1955 \\
\text { Nov. } 25 \sim 28,1955 \\
\text { Mar. } 22 \sim 25,1956\end{array}$ & $\begin{array}{l}\text { Oct. 31, } 1954 \\
\text { Mar. 29, } 1955 \\
\text { Nov. 22,1955 } \\
\text { Mar. 13 15, } 1956\end{array}$ & $\begin{array}{l}\text { North West of Japan } \\
\text { Nevada, U.S.A.* } \\
\text { Near L. Baikal, USSR** } \\
\text { Unknown }\end{array}$ & $\begin{array}{l}1.2 \times 10^{-7} \mu \mathrm{c} / l \\
43 \times 10^{-8} \mu \mathrm{c} / l \\
\text { (not observed) } \\
1.0 \times 10^{-7} \mu \mathrm{c} / l\end{array}$ \\
\hline
\end{tabular}

* Official anouncement of A.E.C., U.S.A.

* Presumption from abnormal barographic oscillation in Japan.

Concerning the observation date, March 22, 1956, the presumptive method of the detonation date is shown in Figs. 5 and 6 , because the decay curve of fission product is expressed in the following formula:

$$
A=A_{0} t^{-\alpha},
$$

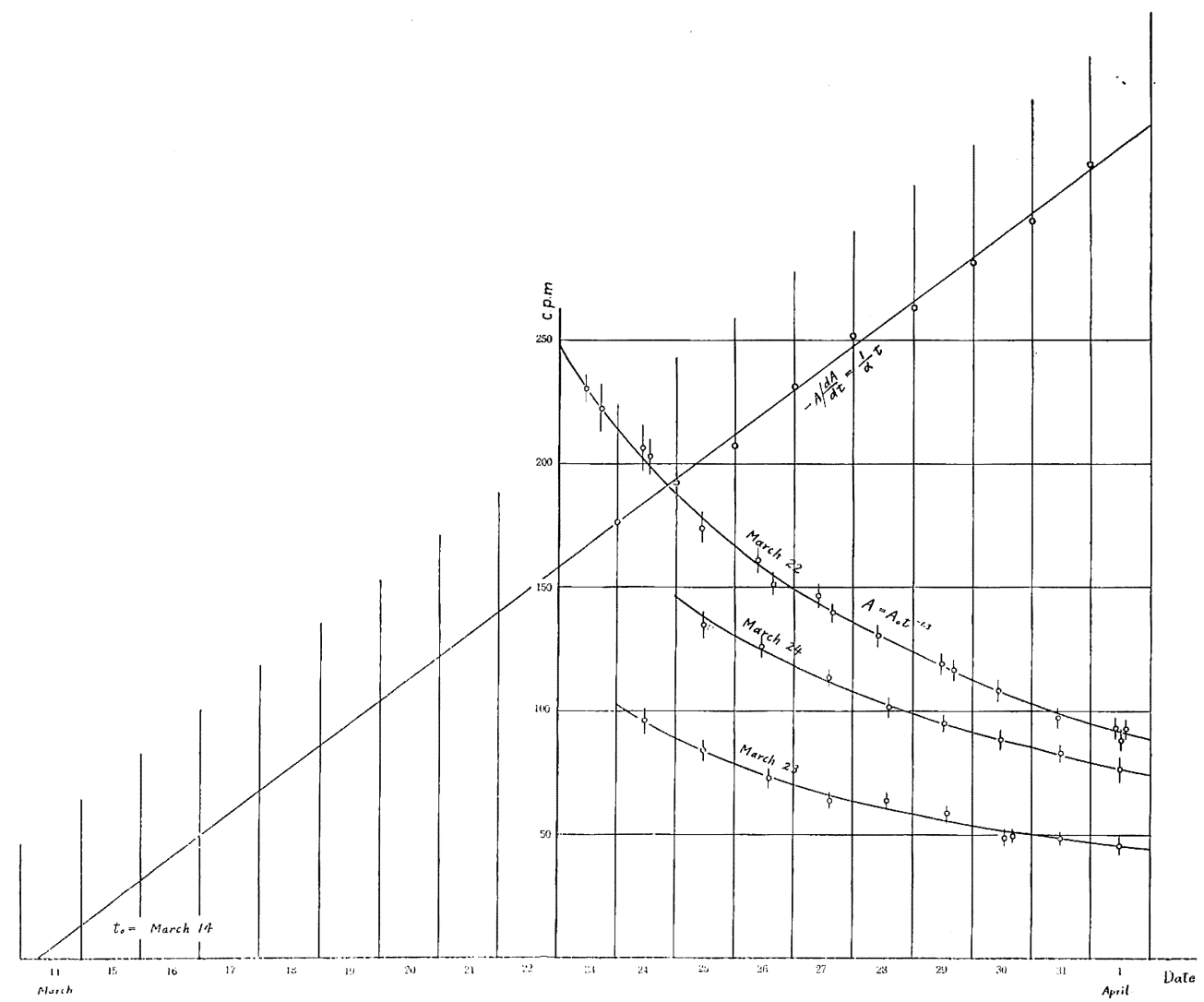

Fig. 5. The presumptive method of the detonation date. 


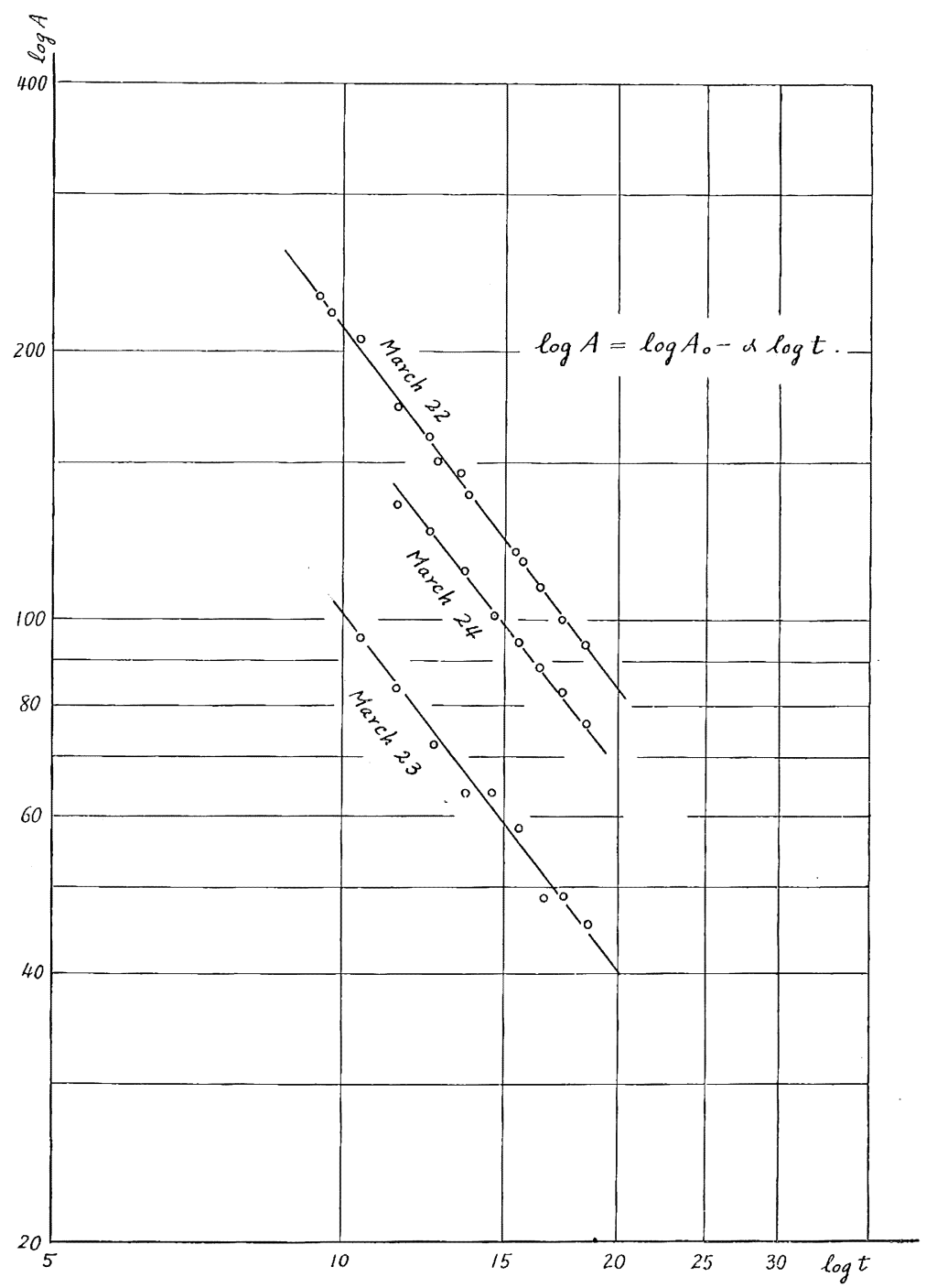

Fig. 6: The presumption method of the detonation date.

$$
A / \frac{d A}{d t}=-\frac{A_{0} t^{-\alpha}}{-\alpha A_{0} t^{-\alpha-1}}=-\frac{1}{\alpha} t,
$$

(5)

$$
\log A=\log A_{0}-\alpha \log t
$$

Acknowledgement__ The authors wish to express their appreciation to Dr. K. Itoo, Mr. C. Ishit, Mr. M. Ogawara, Mr. S. Koshi and the staff members of the Investigation Group of A-H Bomb of this institute for their kind and interest. ing suggestions throughout the work. The authors are indebted to Mr. S. OTA, 
Mr. K. Morita and Mr. K. Fukui of the observation division, Central Meteorological Observatory for kind arrangements for measurement of radioactivity. This work was supported by a special research grant by the Ministry of Education.

\section{References}

[1] Drinker, P. and T. Hatch, 1954: A-C Precipitator. Industrial Dust, p. 157.

[2] Kosht, S., 1953: A Lightweight Electric Precipitator. Journ. Sci. Lab. 29, No. 10.

[3] Junge, CHR, 1953: Die Rolle der Aerosole und der Gasförmigen Beimengungen der Luft in Spurenstoff haushalt der Troposphäre. Tellus, 5, p. 1.

[4] MiYake, Y. and Y. Sugiura, 1950 : The Mechanism of Disolution of the Atmospheric Chloride into Rain Water. Pap. Met. Geophys., 1, p. 222.

[5] Morita, K. and K. FuKU1, 1956: On the Variation of Radioactivity of Rain (in Japanese). Tenki (Weather), 3, No. 1, p. 29.

[6] Widkining, M.H., 1952: Natural Radioactivity as a Tracer in the Rating of Aerosols According to Mobility. Rev. Sci. Inst. 23, p. 13.

[7] T.umla, E. and T. Doks, 1954: The Airborne Radioactivity (in Japanese). Kagaku (Science), 26, p. 124.. 